\title{
CONCEPTS
}

\section{Fresh Low Titer O Whole Blood Transfusion in the Austere Medical Environment}

\author{
Alison Matthews, $\mathrm{MD}^{1,2}$; Steven G. Schauer, DO, MS ${ }^{3,4,5,6}$; Andrew D. Fisher, MPAS, PA-C ${ }^{7,8,9}$ \\ ${ }^{I}$ Northshore University Healthsystem, Highland Park, IL; ${ }^{2}$ University of Chicago, Chicago, IL; ${ }^{3}$ US Army Institute of Surgical Research, JBSA Fort Sam, \\ Houston, TX; ${ }^{4}$ 59th Medical Wing, JBSA, Lackland, TX; ${ }^{5}$ Brooke Army Medical Center, JBSA Fort Sam, Houston, TX; ${ }^{6}$ Uniformed Services University \\ of the Health Sciences, Bethesda, MD; ${ }^{7}$ Medical Command, Texas Army National Guard, Austin, TX; ${ }^{8}$ Texas A\&M College of Medicine, Temple, TX; \\ ${ }^{9}$ Prehospital Research in Military and Expeditionary Environments (PRIME2), San Antonio, TX
}

\begin{abstract}
Massive hemorrhage is an immediate threat to life. The military developed the Tactical Combat Casualty Care guidelines to address the management of acute trauma, including administration of blood products. The guidelines have been expanded to include low titer $\mathrm{O}$ whole blood, which is in limited use by the military. This proposal describes how the transfusion of fresh whole blood might be applied to the remote civilian environment. In doing so, this life-saving intervention may be brought to the austere medical environment, allowing critically hemorrhaging patients to survive to reach definitive medical care.
\end{abstract}

Keywords: hemorrhage, hemorrhagic shock, remote damage control resuscitation, tactical combat casualty care

\section{Introduction}

Wilderness and military prehospital practitioners face similar challenges in providing medical care. Some factors relate to the austere, remote, and harsh environments that are frequently encountered. Constraints in the availability and functionality of medical resources and personnel in isolated locations also occur. Both wilderness and military operations may involve prolonged evacuation times and delays before reaching definitive care. Early utilization of blood transfusion has improved survivability during recent conflicts. ${ }^{1}$ Therefore, transfusion capabilities at the point of injury (POI) may be lifesaving. There are significant opportunities to advance wilderness medical care by incorporating the battlefield lessons learned by military providers.

In 2016 the Wilderness Medical Society hosted a Tactical Combat Casualty Care (TCCC) preconference at the Seventh World Congress of Mountain \& Wilderness Medicine in Telluride, Colorado. At this preconference, subject matter experts presented substantial contributions to

Corresponding author: Alison Matthews, MD, Northshore University Healthsystem, University of Chicago Anesthesiology 777 Park Ave, West Highland Park, IL 60093; e-mail: amatthews@ northshore.org.

Submitted for publication May 2019.

Accepted for publication August 2019. wilderness medicine by way of lessons learned from the military. These proceedings were subsequently published. ${ }^{2}$ Information presented here highlights and expands the understanding of one previously published principle, the practice of low titer group $\mathrm{O}$ whole blood (LTOWB) transfusion. $^{3}$

\section{Background}

Hemorrhage is the leading cause of potentially preventable death in combat injuries. ${ }^{4}$ The model of damage control resuscitation emerged to address the high fatality rate of traumatic injuries. ${ }^{5}$ The basic principles are rapid identification of hemorrhagic shock, mechanical and pharmacologic hemorrhage control, hemostatic resuscitation to maintain cerebral perfusion, and permissive hypotension. ${ }^{6}$ These interventions improve survival by means of hemostasis and maintenance of circulating volume while avoiding acidosis, hypothermia, and coagulopathy. ${ }^{3}$ Remote damage control resuscitation is the application of these principles to the prehospital environment.

Effective implementation of hemostatic resuscitation at the POI is a particular challenge. There is now consensus that balanced blood-based replacement strategies result in improved outcomes. ${ }^{8}$ Current TCCC guidelines advocate 
the use of whole blood for resuscitation. ${ }^{9}$ Additionally, short-term survival of combat casualties is significantly improved when blood products can be administered within 34 min of injury. ${ }^{10}$ The provision of "blood far forward" enables transfusion to begin at the POI, improving survivability. ${ }^{11}$

From World War I through the Vietnam War, the military relied on whole blood for the treatment of hemorrhagic shock. During the Vietnam War more than 260,000 units were transfused, with 38 documented transfusion reactions. ${ }^{12}$ The advent of component-based transfusion medicine in the 1970s put an end to this practice. Using lessons learned from recent military conflicts, the practice of whole blood transfusion has been resumed. This is typically supplied as a cold-stored product from an accredited blood banking facility. However, the military has adopted the practice of fresh whole blood transfusion at POI for those instances when delivery of cold-stored blood is not feasible. Fresh whole blood is collected on demand from prescreened donors, which allows transfusion to begin prior to evacuation. ${ }^{13}$ Additionally, this blood does not need to be warmed prior to administration.

Military innovations in hemostatic resuscitation have influenced civilian trauma care. Increasingly, civilian emergency departments maintain whole blood supplies for immediate administration on arrival. ${ }^{14}$ The San Antonio Fire Department emergency medical system in conjunction with University of Texas Southwest medical center have administered in excess of 100 units of whole blood in the prehospital setting. ${ }^{15}$ Subsequently, multiple municipalities across the United States instituted similar prehospital transfusion protocols. Ground and helicopter-based emergency medical services units carry whole blood to initiate transfusion in conjunction with transport to definitive care. ${ }^{16}$ Royal Caribbean International has developed a fresh whole blood transfusion protocol for use on remote cruise expeditions. ${ }^{17}$ Additionally, the petroleum industry has developed whole blood transfusion programs for use on its remote platforms. ${ }^{18}$ In the wilderness setting, several case reports have highlighted the necessity of developing a wilderness transfusion protocol. ${ }^{17,19-21}$ A review of basic transfusion medicine explains how this can be performed safely.

\section{TRANSFUSION MEDICINE}

Human blood types are classified as A, B, and $\mathrm{O}$ and are determined by the expression of carbohydrate chains on the erythrocyte cell membrane. ${ }^{22}$ These chains are not unique to humans and are also expressed by certain bacteria, viruses, and plants. Humans over the age of 3 months begin to develop immunoglobulin $\mathrm{M}$ antibodies to these non-native carbohydrate chains via the intestinal mucosa. ${ }^{22}$
Individuals with group A blood will be antigen positive for group A and will develop anti-B antibodies. An individual with group $\mathrm{O}$ blood does not have any red cell expression of antigens and will develop antibodies to type A and B blood. ${ }^{23}$ Blood group mismatch during transfusion can lead to severe hemolytic transfusion reactions due to $\mathrm{ABO}$ incompatibility. ${ }^{24}$ Recipient antibodies will attack foreign donor cells with resultant hemolysis, hemoglobinuria, disseminated intravascular coagulation, and hypotension. Because group $\mathrm{O}$ red blood cells do not express antigens, recipient antibodies will not be activated on exposure, which reduces the risk of a severe transfusion reaction. ${ }^{24}$

The plasma of $\mathrm{O}$ individuals will contain antibodies to both $\mathrm{A}$ and $\mathrm{B}$ surface antigens. When transfused into non-group $\mathrm{O}$ recipients, these antibodies may initiate a transfusion reaction. However, $\mathrm{O}$ whole blood that has a low titer (low level) of anti-A and anti-B antibodies can be safely transfused across blood groups. Specifically, the plasma of $\mathrm{O}$ whole blood is evaluated for the level of antibodies to A and B surface antigens. This is known as the antibody titer. Although there is no consensus on the definition of low titer, most experts agree that an immunoglobulin $\mathrm{M}$ titer below 1:256 is suitable for use as universal donor blood. ${ }^{13,25}$ This LTOWB can then be used for non-typespecific emergency transfusions with significantly reduced risk of transfusion reactions. ${ }^{26}$

Rhesus ( $\mathrm{Rh}$ ) factor incompatibility is less likely to cause transfusion-related reactions. Of the 50 types of Rh factors, $\mathrm{D}$ incompatibility is the most significant. ${ }^{22}$ Most individuals are $\mathrm{Rh}(\mathrm{D})+$ and do not produce anti-Rh(D) antibodies. However, individuals who are $\mathrm{Rh}(\mathrm{D})-$ may develop antibodies on exposure to $\mathrm{Rh}(\mathrm{D})+$ blood. This sensitization will result in an immunoglobulin $\mathrm{G}$ mediated transfusion reaction on subsequent exposure to $\mathrm{Rh}(\mathrm{D})+$ blood. Alloimmunization is particularly important in women of childbearing age because antibody activation in $\mathrm{Rh}(\mathrm{D})$ - women can lead to fetal hemolysis during pregnancy. ${ }^{27}$ To prevent alloimmunization, $\mathrm{Rh}$ immunoglobulin needs to be administered within 72 of exposure of $\mathrm{Rh}(\mathrm{D})+$ antibodies. $^{28}$ Alloimmunized women require specialty antenatal care to prevent fetal anemia. ${ }^{29}$

\section{TRANSFUSION REACTIONS}

Transfusion reactions can range in severity from mild to severe and can occur acutely or have a delayed onset. These reactions are broadly characterized as immunologic or nonimmunologic reactions. ${ }^{22}$ Immunologic reactions are due to recipient antibodies interacting with donor antigens. These reactions include acute hemolytic, delayed hemolytic, febrile nonhemolytic, simple allergic, and anaphylactic reactions. Immunologic reactions associated with donor anti-HLA and antigranulocyte antibodies result 
in transfusion-related acute lung injury (TRALI). Transfusion-associated circulatory overload (TACO) is a nonimmunologic transfusion reaction caused by rapid intravascular volume expansion in individuals with limited cardiac reserve or impaired renal function. Other nonimmunologic reactions include disease transmission and bacterial contamination, ${ }^{30}$ which typically have a delayed onset. Symptoms of reactions range from mild to severe: urticaria, itching, chills, rigors, temperature elevation, dyspnea, respiratory distress, and hypotension. Mild symptoms can be treated symptomatically. However, evidence of temperature elevation of greater than $1^{\circ} \mathrm{C}\left(2^{\circ} \mathrm{F}\right)$ indicates development of a potentially harmful reaction, and termination of transfusion should be considered before more significant complications result. ${ }^{22}$ If a reaction occurs, the risk of continuing the transfusion must be weighed against the risk of possible death from hemorrhagic shock.

\section{LTOWB}

Transfusion strategies for remote damage control resuscitation can involve group-specific whole blood or LTOWB. Using a group-specific transfusion protocol means each recipient will be matched with a donor from the same blood group. This approach has the advantage of ensuring $\mathrm{ABO}$ compatibility of red cells and plasma. The significant disadvantage of this approach is the risk of a major transfusion reaction if an error occurs. Additionally, group-specific donors may be limited, and resuscitative efforts may be restricted by inadequate supply. ${ }^{31}$

A transfusion strategy based on LTOWB has several advantages. There is ABO compatibility of red cells in all recipients. Crossmatching is unnecessary, and transfusion may begin immediately. There will be a large number of potential donors because $45 \%$ of the population is group $\mathrm{O}^{25}$ and the majority have titers $<1: 256 .^{32}$ The most significant disadvantage is the need to check titers prior to departure. If titer levels are not accurately identified, there is a risk of a minor hemolytic transfusion reaction. There is general consensus that LTOWB is the safest approach to emergency transfusion in the austere environment. ${ }^{31}$

\section{WILDERNESS CONSIDERATIONS}

Applying these techniques to the remote wilderness environment can be complex. Necessary transfusion supplies must be carried because most transfusion equipment cannot be improvised. Collection is limited to a single unit from each donor to avoid physical deterioration. ${ }^{33}$ Although exercise capacity seems to be maintained at sea level, maximum oxygen uptake $\left(\dot{\mathrm{V}}_{2 \text { max }}\right)$ is reduced, which may affect performance at altitude. ${ }^{34}$ Additionally, maintaining aseptic technique in the remote environment can be challenging. For these reasons, fresh whole blood transfusion protocols need to be tailored to fit the unique limitations of the wilderness environment. This protocol has been adapted from several published sources for the austere environment. ${ }^{7,13,17,27,31}$ An outline of the transfusion protocol and a kit list are included in online Appendices 1 and 2. Commercial kits are available from multiple sources.

\section{ASSESSMENT}

Before considering transfusion, the diagnosis of hemorrhagic shock must be confirmed. This involves evaluating the mechanism of hemorrhage, mental status, and hemodynamics. ${ }^{17}$ Palpable pulses for assessing hemodynamic status are advocated by TCCC. These estimates generally overestimate the actual blood pressure. ${ }^{35}$ Therefore, when implementing an advanced intervention, such as whole blood transfusion, it may be beneficial to quantify blood pressure. A simple alternative is to determine the palpable blood pressure. While palpating the pulse, inflate the cuff in $10 \mathrm{~mm} \mathrm{Hg}$ increments until pulse is no longer palpable. Increase pressure by another $10 \mathrm{~mm} \mathrm{Hg}$, and then begin to slowly deflate the cuff. Return of the palpable pulse confirms the systolic pressure. As the cuff deflates, experienced providers will be able to palpate a thrill indicating the diastolic pressure. ${ }^{36}$ In the setting of hemorrhage, a patient with a systolic blood pressure $<100 \mathrm{~mm} \mathrm{Hg}$ and a pulse rate $>100$ beats. $\mathrm{min}^{-1}$ meets the definition of shock. ${ }^{37}$

\section{DONOR SELECTION}

The predeparture briefing is an opportune time to address the idea of fresh whole blood transfusion with the team. Preparing to travel to areas that are remote, inaccessible, or lack a reliable blood supply warrant a discussion about the feasibility of adopting a blood transfusion protocol. The risk of requiring a transfusion during the trip is low, but if needed, suitable donors are prescreened fellow team members. The team will also need to consider the ethical and logistic implications of remote transfusion. Specifically, the team must come to a consensus as to whether a transfusion will be offered only to teammates or also to local citizens, porters, and in-country support staff. With these parameters clearly defined, volunteers from the team can then be identified as potential donors. Informed consent is obtained from these individuals and can be revoked at any time. Blood donation should be considered purely voluntary.

All team members should have confirmatory ABO testing well in advance of departure. Donors who have group O blood will undergo further testing to determine antibody titer levels. These levels can change over time and may require periodic confirmation. ${ }^{38,39}$ The most desirable donors are males with low titer O blood $(<1: 256)$. Blood obtained from female donors who have been pregnant 
may be associated with TRALI and other transfusion reactions. Women should not be considered first-line donors until further research provides a more accurate assessment of this risk. ${ }^{40}$ Additionally, family members should not serve as donors to their genetic relatives because of the risk of graft versus host disease. ${ }^{16}$ If no LTOWB donors are identified, consideration can be given to using any available group $\mathrm{O}$ donors. The risk of death from hemorrhagic shock outweighs the risk of a minor transfusion reaction. ${ }^{41}$

In addition to typing, volunteer donors should be tested for transfusion-related infections including hepatitis B, hepatitis C, HIV, and syphilis. ${ }^{42}$ Vaccination schedules should be completed before travel. An additional complexity during travel to areas with arthropod-borne illnesses is the risk of transmission via blood transfusion. These illnesses include West Nile virus, Zika, malaria, Chagas disease, babesiosis, leishmaniasis, and Lyme disease. On expeditions to endemic areas, effective vector control is important. Additionally, only donors who are feeling well should be used for collection.

\section{LTOWB TRANSFUSION PROTOCOL FOR THE AUSTERE ENVIRONMENT}

Before instituting a LTOWB transfusion protocol, team members require training in the science and practice of transfusion medicine. Undertaking transfusion of fresh whole blood can involve significant risks if not meticulously conducted. With appropriate training, transfusion in the austere environment can be lifesaving in the setting of hemorrhagic shock.

Once the need for emergency transfusion is identified, the fresh whole blood transfusion protocol is instituted, and a volunteer donor is sought. Potential donors should be questioned about any recent engagement in high-risk sexual behaviors, illicit drug use, arthropod exposure, and illnesses. Men are preferred donors. Female donors are used once the male donor pool is exhausted. If the recipient is female and of childbearing age, the highest priority donor is a low titer $\mathrm{O} R(\mathrm{D})$ - male. $\mathrm{Rh}(\mathrm{D})+$ donors may be used, but alloimmunization is a significant risk to future pregnancies. $^{27}$

With the donor identified, the first step is to obtain blood samples from the donor and recipient. A $12 \mathrm{~mL}$ sample is needed to fill red and lavender top vacutainers, which are saved for retrospective testing. Additionally, a few drops are used to complete a point-of-care ABO test kit. This serves as another level of safety, reconfirming the blood types of the donor and recipient. All samples collected need to be clearly labeled with the individual's name and birthdate, the date and time of collection, and the initials of the person who drew the samples. On return to definitive care, these will be used for testing of blood type, hemoglobin concentration, and transmissible diseases. It is of particular importance to obtain a pretransfusion sample from the recipient because blood typing can be difficult once non-type-specific blood has been transfused. ${ }^{27}$

A large antecubital vein is identified and punctured by the needle of the collection bag, which is filled passively by gravity. Gentle agitation is used to fully mix the anticoagulant and prevent clotting. To prevent overfilling, a length of cord is tied around the waist of the collection bag to a circumference of $18 \mathrm{~cm}$ (7 in). Alternatively, a zip tie premarked at $18 \mathrm{~cm}$ (7 in) may be used. This simple procedure removes the need to weigh the bag and reliably prevents the collected volume from exceeding $450 \mathrm{~mL} .{ }^{43}$ This blood should be transfused within 6 h. Encourage the donor to maintain nutrition and hydration during donation. After a brief observation period of $15 \mathrm{~min}$, donors may return to normal activities at their discretion.

Intravenous or intraosseous access ${ }^{44}$ is obtained in the recipient. The collected blood is delivered via blood filter tubing. Blood should be allowed to flow via gravity but may require application of pressure if using intraosseous access. ${ }^{45}$ The recipient should be continually evaluated for evidence of a possible transfusion-related reaction. Rigors, elevated temperature, flank pain, dark urine, and shortness of breath are all indications of a significant transfusionrelated reaction. Treatment includes cessation of transfusion, administration of $\mathrm{H} 1$ and $\mathrm{H} 2$ blockers, steroids, and acetaminophen. TRALI and TACO can be difficult to distinguish without sophisticated testing. Diuretic administration can be considered. Most reactions occur within $4 \mathrm{~h}$ of transfusion, but some can be delayed; observation should be ongoing.

In addition to observing for any signs of transfusion reaction, it is important to continually assess hemodynamic status. It can be challenging to determine when to stop volume resuscitation and proceed to observation and supportive care. SBP $>100 \mathrm{~mm} \mathrm{Hg}$ and heart rate $<100$ beats. $\mathrm{min}^{-1}$ can serve as useful information to guide this decision. Generally, transfusion of any collected unit of blood should be completed once started. Units should be collected sequentially to avoid wasting blood that will not be used. Advance planning for additional units needs to account for the fact that collection of a single unit of blood takes approximately $25 \mathrm{~min}$. If there is no response to transfusion of the initial 3 to 4 units, consideration should be given to terminating resuscitative efforts. ${ }^{7}$

All supplies used for collection and transfusion are retained for retrospective testing. Careful documentation of the transfusion process in the medical team leader's log is necessary, including background of events, participants present, assessment of patient, rationale for decision to transfuse, vital signs before and after collection for donors and every $15 \mathrm{~min}$ for the recipient until arrival at definitive 
care, disposition of donor postcollection, recipient's response to transfusion, assessment for further transfusion, contact with evacuation services, and plans for transport. All records and supplies should be retained by the expedition medic until a complete debrief can occur with all concerned parties.

\section{Conclusions}

Lessons learned from recent military conflicts have brought low titer $\mathrm{O}$ whole blood to the forefront of resuscitative measures for acute hemorrhage. Prompt implementation of whole blood transfusion for hemostatic resuscitation of hemorrhagic shock may be lifesaving. In this review, we present our recommendations for implementing this practice in the wilderness environment. Predeparture team education is important for safe transfusion practice. Team members require blood typing, antibody titer, and transfusion-transmissible infection testing to determine donor eligibility. Point-of-care testing to reconfirm donor blood type in the field can provide an additional layer of safety. Additional concerns related to the wilderness environment include prevention of arthropod-borne infections and maintenance of aseptic transfusion technique. Reduction in $\dot{\mathrm{V}}_{2}$ max after donation may affect the performance of the wilderness expedition participant, particularly at altitude. The expedition medic documents and retains all transfusion-related supplies for retrospective testing. A team debrief at the conclusion of the expedition can be a valuable opportunity to address questions and concerns about the transfusion process. Additional research is warranted to refine this practice for the austere medical environment.

Author Contributions: Concept of manuscript, design, and drafting of manuscript (AM, SS, AF).

Financial/Material Support: None.

Disclosures: None.

\section{Supplementary materials}

Supplementary material associated with this article can be found in the online version at https://doi.org/10.1016/j. wem.2019.08.006.

\section{References}

1. Kotwal RS, Scott LLF, Janak JC, Tarpey BW, Howard JT, Mazuchowski EL, et al. The effect of prehospital transport time, injury severity, and blood transfusion on survival of US military casualties in Iraq. J Trauma Acute Care Surg. 2018;85(1S Suppl 2):S112-21.

2. Llewellyn C. Tactical combat casualty care: transitioning battlefield lessons learned to other austere environmentskeynote lecture: the symbiotic relationship between operational military medicine, tactical medicine, and wilderness medicine: a view through a personal lens. Wilderness Environ Med. 2017;28(2S):S6-11.

3. Chang R, Eastridge B, Holcomb J. Tactical combat casualty care: transitioning battlefield lessons learned to other austere environments: remote damage control resuscitation in austere environments. Wilderness Environ Med. 2017;28(2S): S124-34.

4. Eastridge B, Mabry R, Seguin P, Cantrell J, Tops T, Uribe P, et al. Death on the battlefield (2001-2011): implications for the future of combat casualty care. J Trauma Acute Care Surg. 2012;73(6 Suppl 5):S431-7.

5. Spinella P, Holcomb J. Resuscitation and transfusion principles for traumatic hemorrhagic shock. Blood Rev. 2009;23(6):231-40.

6. Jenkins D, Rappold J, Badloe J, Berséus O, Blackbourne L, Brohi K, et al. THOR position paper on remote damage control resuscitation: definitions, current practice and knowledge gaps. Shock. 2014;41(Suppl 1):3-12.

7. Fisher A, Washbum G, Powell D, Callaway D, Miles E, Brown J, et al. Damage control resuscitation in prolonged field care. J Spec Oper Med. 2018;18(3):109-19.

8. Bhangu A, Nepogodiev D, Doughty H, Bowley D. Meta-analysis of plasma to red blood cell ratios and mortality in massive blood transfusions for trauma. Injury. 2013;44(12): 1693-9.

9. Butler J, Holcomb J, Shackelford S, Barbabella S, Bailey J, Baker J, et al. Advanced resuscitative care in Tactical Combat Casualty Care: TCCC guidelines change 18-01:14 October 2018. J Spec Oper Med. 2018;18(4):37-55.

10. Shackelford S, del Junco D, Powell-Dunford N, Mazuchowski E, Howard J, Kotwal R, et al. Association of prehospital blood product transfusion during medical evacuation of combat casualties in Afghanistan with acute and 30day survival. JAMA. 2017;318(16):1581-91.

11. Cap A, Pidcoke H, DePasquale M, Rappold J, Glassberg E, Eliassen $\mathrm{H}$, et al. Blood far forward: time to get moving! J Trauma Acute Care Surg. 2015;78(6 Suppl 1):S2-6.

12. Neel M. Vietnam Studies: Medical Support of the US Army in Vietnam 1965-1970. Washington, DC: United States Department of the Army; 1973:122-3.

13. Cap A, Beckett A, Benov A, Borgman M, Bryant B, Chen J. Joint trauma system clinical practice guideline: whole blood transfusion, 2-39. Available from: https://jts.amedd.army. mil/index.cfm/PI_CPGs/cpgs. Accessed March 17, 2019.

14. McGinity A, Zhu C, Greebon L, Xenakis E, Waltman E, Epley E, et al. Prehospital low-titer cold-stored whole blood: philosophy for ubiquitous utilization of O-positive product for emergency use in hemorrhage due to injury. J Trauma Acute Care Surg. 2018;84(6 Suppl 1):S115-9.

15. Weymouth W, Long B, Koyfman A, Winckler C. Whole blood in trauma: a review for emergency clinicians. J Emerg Med. 2019;56(5):491-8.

16. Zielinski M, Stubbs J, Berns K, Glassberg E, Murdock A, Shinar E, et al. Prehospital blood transfusion programs: capabilities and lessons learned. J Trauma Acute Care Surg. 2017;82(6):S70-8.

17. Strandenes G, Hervig T, Bjerkvig C, Williams S, Eliassen H, Fosse $\mathrm{T}$, et al. The lost art of whole blood transfusion in 
austere environments. Curr Sports Med Rep. 2015;14(2): 129-34.

18. Sicard B, Marouzé F, Roche C, Carron M, Ausset S, Sailliol A. Bleeding management in remote environment: the use of fresh whole blood transfusion and lyophilised plasma. Int Marit Health. 2016;67(2):79-82.

19. Carron M, Globokar P, Sicard BA. Acute gastrointestinal haemorrhage on board a cruise ship in the Antarctic Peninsula. Int Marit Health. 2016;67(4):223-6.

20. Grocott M, McCorkell S, Cox M. Case report: resuscitation from hemorrhagic shock using rectally administered fluids in a wilderness environment. Wilderness Environ Med. 2005;16(4):209-11.

21. Wu T, Ding S, Liu J, Jia J, Dai R, Zhu D, et al. High-altitude gastrointestinal bleeding: an observation in Qinghai-Tibetan railroad construction workers on Mountain Tanggula. World J Gastroenterol. 2007;13(5):774-80.

22. Blood transfusion. In: Lock S, Last J, Dunea G, eds. Oxford Illustrated Companion to Medicine. 3rd ed. Oxford, England: Oxford University Press; 2001:117-20.

23. Daniels G, Reid M. Blood groups: the past 50 years. Transfusion. 2010;50(2):281-9.

24. Delaney M, Wendel S, Bercovitz R, Cid J, Cohn C, Dunbar N, et al. Review: transfusion reactions: prevention, diagnosis, and treatment. Lancet. 2016;388:2825-36.

25. Fisher A, Miles E, Cap A, Strandenes G, Kane S. Tactical damage control resuscitation. Mil Med. 2015;180(8):869-75.

26. Seheult J, Bahr M, Anto V, Alarcon L, Corcos A, Sperry J, et al. Safety profile of uncrossmatched, cold-stored, lowtiter, group $\mathrm{O}$ plus whole blood in civilian trauma patients. Transfusion. 2018;58(10):2280-8.

27. Benavides L, Smith I, Benavides J, Bowley D, Doughty H, Lundy J. Deployed skills training for whole blood collection by a special operations expeditionary surgical team. J Trauma Acute Care Surg. 2017;82(6 Supp 1):S96-102.

28. Yazer MH, Waters JH, Spinella PC, Cap CA, Fahie CRL Sr, Gourdine E, et al. Use of uncrossmatched erythrocytes in emergency bleeding situations. Anesthesiology. 2018;128(3): 650-6.

29. Mayer B, Hinkson L, Hillebrand W, Henrich W, Salama A. Efficacy of antenatal intravenous immunoglobulin treatment in pregnancies at high risk due to alloimmunization to red blood cells. Transfus Med Hemother. 2018;45(6):429-36.

30. Hong H, Xiao W, Lazarus H, Good C, Maitta R, Jacobs M. Detection of septic transfusion reactions to platelet transfusions by active and passive surveillance. Blood. 2016;127(4):496-502.

31. Strandenes G, Berseus O, Cap A, Hervig T, Reade M, Prat N, et al. Low titer group $\mathrm{O}$ whole blood in emergency situations. Shock. 2014;41(Suppl 1):70-5.

32. Beddard R, Ngamsuntikul S, Wafford T, Aranda L. Immunoglobulin $\mathrm{M}$ anti-A and anti-B titers in South Texas group O D+ male donors. Transfusion. 2019;59:2207-10.

33. Strandenes G, Skogrand H, Spinella P, Hervig T, Rein E. Donor performance of combat readiness skills of special forces soldiers are maintained immediately after whole blood donation: a study to support the development of a prehospital fresh whole blood transfusion program. Transfusion. 2013;53(3):526-30.

34. Eliassen HS, Hervig T, Backlund S, Sivertsen J, Iversen VV, Kristoffersen M, et al. Immediate effects of blood donation on physical and cognitive performance: a randomized controlled double-blinded trial. J Trauma Acute Care Surg. 2018;84(6S Suppl 1):S125-31.

35. Deakin C, Low J. Accuracy of the advanced trauma life support guidelines for predicting systolic blood pressure using carotid, femoral, and radial pulses: observational study. BMJ. 2000;321(7262):673-4.

36. Sahu D, Bhaskaran M. Palpatory method of measuring diastolic blood pressure. J Anaesthesiol Clin Pharmacol. 2010;26(4):528-30.

37. Eastridge B, Salinas J, Wade C, Blackbourne L. Hypotension is $100 \mathrm{~mm} \mathrm{Hg}$ on the battlefield. Am J Surg. 2011;202(4): 404-8.

38. Sprogøe U, Yazer M, Rasmussen M, Antonsen B, Bistrup C, Assing K. Minimal variation in anti-A and -B titers among healthy volunteers over time: implications for the use of outof-group blood components. J Trauma Acute Care Surg. 2017;82(6S Suppl 1):S87-90.

39. Bailey J, Fisher A, Yazer M, Howard J, Corley J, Miles E, et al. Changes in donor antibody titer levels over time in a military group O low-titer whole blood program. Transfusion. 2019;59(S2):1499-506.

40. Caram-Deelder C, Kreuger AL, Evers D, de Vooght KMK, van de Kerkhof D, Visser O, et al. Association of blood transfusion from female donors with and without a history of pregnancy with mortality among male and female transfusion recipients. JAMA. 2017;318(15):1471-8.

41. Bersus O, Boman K, Nessen S, Westerberg L. Risks of hemolysis due to anti-A and anti-B caused by the transfusion of blood or blood components containing ABO-incompatible plasma. Transfusion. 2013;53(Suppl 1):S114-23.

42. Strandenes G, De Pasquale M, Cap AP, Hervig TA, Kristoffersen E, Hickey M, et al. Emergency whole-blood use in the field: a simplified protocol for collection and transfusion. Shock. 2014;41(Suppl 1):76-83.

43. Meledeo M, Fisher A, Peltier G, Miles E, Muse W, Kerr W, et al. Volumetric control of whole blood collection in austere environments. J Trauma Acute Care Surg. 2017;82(6 Suppl 1):S26-32.

44. Bjerkvig C, Fosse T, Apelseth T, Sivertsen J, Braathen H, Eliassen $\mathrm{H}$, et al. Emergency sternal intraosseous access for warm fresh whole blood transfusion in damage control resuscitation. J Trauma Acute Care Surg. 2018;84(6 Suppl 1): S120-4.

45. Auten JD, Mclean JB, Kemp JD, Roszko PJ, Fortner GA, Krepela AL, et al. A pilot study of four intraosseous blood transfusion strategies. $J$ Spec Oper Med. 2018;18(3):50-6. 